\section{Mordedura de víbora}

\section{Sr. Director:}

La mordedura de serpiente constituye un cuadro poco frecuente en España, pero potencialmente grave y con una mortalidad entre 3-7 muertes/año (1). Su escasa divulgación en la literatura médica y la poca información que se tiene en los servicios hospitalarios de urgencias y centros de salud, hace que el abordaje de estos pacientes esté escasamente protocolizado y con variabilidad en la práctica clínica. Por todo ello hemos revisamos las caracteristicas de 7 pacientes con mordedura de víbora recogidos en nuestro hospital durante 10 años (Tabla I).

En nuestro país hay 5 especies de serpientes venenosas: tres de la familia de las víboras ("viperidae") Vipera latastei, es la más abundante y menos tóxica, Vipera aspis, es la de tóxico más activo y Vipera berus hispánica o seoanei (2-4). Y dos de la familia de las culebras ("colubridae"). El diagnóstico definitivo de mordedura por serpiente venenosa se basa en la identificación positiva de la serpiente, que debería ser llevada al centro sanitario, junto con la clínica o manifestaciones del envenenamiento (3). El mayor número de mordeduras se produce entre marzo y octubre, generalmente afectan al miembro superior y están en relación con actividades agrarias $(5,6)$. El grado de envenenamiento está determinado por factores dependientes del ofidio, del sujeto, edad, estado de salud, localización de la lesión (en la cabeza y en el tronco se duplica la gravedad) y rapidez en la instauración del tratamiento (7). Entre las manifestaciones locales, primero se produce dolor variable en el punto de la mordedura. A los 15-45 minutos aparece eritema que rodea dos orificios separados 6-10 $\mathrm{mm}$. Luego edema y/o manchas equimóticas, que pueden progresar hacia la raíz del miembro, con aparición de adenopatías y flictenas. Estas lesiones alcanzan su extensión máxima en 48 horas y pueden sobreinfectarse, de lo contrario desaparecen a los 7-10 días con restituo ad integrum. La manifestación general más común es el "terror", lo cual produce náuseas/vómitos, diarrea, síncope, taquicardia o sudoración (5). Las alteraciones analíticas más frecuentes son hipofibrinogenemia, trombopenia, prolongación del tiempo de quick e insuficiencia renal. Por consenso se han establecido 4 grados de lesión: Grado 0 , sólo señales de punción. Grado I, además reacción inflamatoria local. Grado II, la reacción afecta a toda la extremidad, con clínica general leve. Grado III, desborda la raíz del miembro y/o clínica general moderada/severa y posible coagulopatía $(7,8)$. El tratamiento debe iniciarse lo antes posible. Se basa en reposo, inmovilizar el miembro afectado y elevarlo manteniéndolo por debajo de la altura del corazón, limpieza y desinfección de la zona y medidas de soporte generales. En caso de síndrome compartimental, fasciotomía (6). La incisión y succión de la herida, la aplicación de torniquetes o frío local es muy discutida y en general se desaprueban $(5,9,10)$. El suero antiofídico (SAO) es el único tratamiento específico disponible para mordeduras de serpientes venenosas; se solicita al Servicio de Farmacia, se adquiere a través de la Sección de Medi-

TABLA I

CARACTERÍSTICAS CLÍNICAS, ANALÍTICAS, TRATAMIENTO Y EVOLUCION DE LOS PACIENTES CON MORDEDURA DE VÍBORA

\begin{tabular}{|c|c|c|c|c|c|c|c|}
\hline & Caso 1 & Caso 2 & Caso 3 & Caso 4 & Caso 5 & Caso 6 & Caso 7 \\
\hline Sexo & Varón & Varón & Varón & Varón & Varón & Mujer & Mujer \\
\hline Edad & 46 & 76 & 25 & 26 & 38 & 45 & 47 \\
\hline Lugar & Playa & Campo & Campo & Campo & Monte & Campo & Campo \\
\hline Mes & Septiembre & Septiembre & Septiembre & Septiembre & Abril & Julio & Septiembre \\
\hline Ingreso & 3 días & 3 días & 3 días & 5 días & 4 días & 4 días & 4 días \\
\hline $\begin{array}{l}\text { Localización } \\
\text { de la mordedura }\end{array}$ & $\begin{array}{l}1^{0} \text { dedo mano } \\
\text { izq }\end{array}$ & $\begin{array}{l}5^{0} \text { dedo mano } \\
\text { dcha. }\end{array}$ & $\begin{array}{l}2^{\circ} \text { dedo mano } \\
\text { izq. }\end{array}$ & $\begin{array}{l}\text { Zona interdigital } \\
4-5^{\circ} \text { dedo mano izq. }\end{array}$ & Dorso pie izq. & $\begin{array}{l}\text { Maléolo interno } \\
\text { pie izq. }\end{array}$ & $\begin{array}{l}1^{0} \text { dedo pie } \\
\text { dcho. }\end{array}$ \\
\hline $\begin{array}{l}\text { Manifestaciones } \\
\text { locales }\end{array}$ & $\begin{array}{l}\text { Inflamación y } \\
\text { edema de mano }\end{array}$ & $\begin{array}{l}\text { Inflamación y } \\
\text { edema hasta } \\
\text { antebrazo }\end{array}$ & $\begin{array}{l}\text { Inflamación y } \\
\text { edema hasta } \\
\text { antebrazo }\end{array}$ & $\begin{array}{l}\text { Inflamación, edema } \\
\text { y equimosis hasta } \\
\text { antebrazo }\end{array}$ & $\begin{array}{l}\text { Inflamación, edema } \\
\text { y equimosis hasta } \\
\text { raíz de miembro. } \\
\text { Hematoma en } \\
\text { hueco poplíteo }\end{array}$ & $\begin{array}{l}\text { Inflamación, edema } \\
\text { y equimosis hasta } \\
\text { raíz de miembro }\end{array}$ & $\begin{array}{l}\text { Inflamación, edema } \\
\text { y equimosis hasta } \\
\text { rodilla }\end{array}$ \\
\hline $\begin{array}{l}\text { Manifestaciones } \\
\text { sistémicas }\end{array}$ & $\begin{array}{l}\text { Dolor } \\
\text { Escalofríos } \\
\text { Mareo } \\
\text { Naúseas/vómitos }\end{array}$ & Dolor & Dolor & $\begin{array}{l}\text { Dolor } \\
\text { Naúseas/vómitos } \\
\text { Dolor abdominal } \\
\text { Diarrea } \\
\text { Hipotensión }\end{array}$ & $\begin{array}{l}\text { Dolor } \\
\text { Naúseas/vómitos }\end{array}$ & $\begin{array}{l}\text { Dolor } \\
\text { Síncope } \\
\text { Naúseas/vómitos }\end{array}$ & $\begin{array}{l}\text { Dolor } \\
\text { Hipotensión }\end{array}$ \\
\hline Grado de lesión & Grado I & Grado I & Grado I & Grado II & Grado II & Grado II & Grado I \\
\hline Analitica & $\begin{array}{l}\text { Leucocitosis } \\
\text { Creatinina } \\
1,5 \mathrm{mg} / \mathrm{dl}\end{array}$ & & Leucocitosis & Leucocitosis & Leucocitosis & $\begin{array}{l}\text { Leucocitosis } \\
\text { Tasa protombrina } \\
70 \%\end{array}$ & $\begin{array}{l}\text { Leucocitosis } \\
\text { Tasa protombrina } \\
82 \%\end{array}$ \\
\hline Tratamiento & $\begin{array}{l}\text { SAO } \\
\text { VT } \\
\text { Amoxicilina- } \\
\text { clavulánico } \\
\text { AINE }\end{array}$ & $\begin{array}{l}\text { SAO } \\
\text { VT } \\
\text { Amoxicilina- } \\
\text { clavulánico }\end{array}$ & $\begin{array}{l}\text { SAO } \\
\text { VT } \\
\text { Ciprofloxacin* } \\
\text { AINE } \\
\text { Corticoides } \\
\text { HBPM }\end{array}$ & $\begin{array}{l}\text { SAO } \\
\text { VT } \\
\text { Amoxicilina- } \\
\text { clavulánico } \\
\text { AINE }\end{array}$ & $\begin{array}{l}\text { No SAO } \\
\text { VT } \\
\text { Amoxicilina- } \\
\text { clavulánico } \\
\text { Corticoides } \\
\text { HBPM }\end{array}$ & $\begin{array}{l}\text { SAO } \\
\text { VT } \\
\text { Amoxicilina- } \\
\text { clavulánico } \\
\text { Corticoides } \\
\text { HBPM }\end{array}$ & $\begin{array}{l}\text { No SAO } \\
\text { VT } \\
\text { Amoxicilina- } \\
\text { clavulánico } \\
\text { AINE } \\
\text { Corticoides }\end{array}$ \\
\hline
\end{tabular}


camentos Extranjeros; restringiendo su uso al medio hospitalario dado el riesgo de anafilaxia y/o enfermedad del suero. Se aceptan como indicaciones, aunque no están rigurosamente definidas, la rápida extensión local, grado lesional III y/o envenenamiento sistémico. La realización de una prueba de hipersensibilidad previa y la premedicación con antihistamínicos y/o corticoides es motivo de controversia (6-8); así como el tiempo máximo a partir del cual no es eficaz $(6,10)$, pero en cualquier caso se recomienda su administración lo más precoz posible. La forma más frecuente de administración es intravenosa, una ampolla diluida en $500 \mathrm{cc}$ de solución fisiológica a pasar en 4 horas, puede repetirse a las 8 horas según la evolucion clínica (7). El tratamiento se completa con profilaxis antitetánica (correcta vacunación), antibiótica (amoxicilina-clavulánico) y antitrombótica (heparina de bajo peso molecular) $(6,8)$. No hay acuerdo respecto al uso de corticoides (8). El paciente asintomático debe permanecer en observación 4-6 horas y el sintomático al menos 24 horas. El pronóstico en adultos sanos en general es favorable, más cuanto más precozmente haya sido tratado. Las medidas de prevención consisten en métodos de barrera y evitar lugares frecuentados por serpientes.

\section{E. M. Fonseca Aizpurua, E. García Piney ${ }^{1}$, F. J. Nuño Mateo, A. Braña Rodríguez ${ }^{1}$}

Servicios de Medicina Interna ${ }^{\prime}$ Medicina Intensiva. Hospital de Cabueñes. Gijón

1. González D. Clinical aspects of bites by spiders in Spain. Toxicon 1982; 20: 349-353

2. García Piney E, Fonseca Aizpuru EM, Nuño Mateo FJ. Mordedura de víbora. Med Clin 2005; 125: 240.

3. Sanz Anquela JM, Goberna Burguera F, Rodríguez Manzanilla L, Ruiz Liso JM. Lesiones por mordedura de serpiente. Med Clin (Barc) 1989; 92: 398.

4. Meseguer Ruiz VA, Medrano González F, Alamillo S, Ferreras Fernández P. Ritmo idioventricular acelerado y bloqueo incompleto de la rama derecha secundarios a mordedura de Vipera latasti. Med Clin (Barc) 1999; 112: 278-279.

5. Gold BS, Dart RC, Barish RA. Bites of venomus snakes. N Engl J Med 2002; 347: 347-356.

6. Anglés R, Salgado A, Peracaula R, Bóveda JL, Latorre F, Palomar m. Mordeduras de serpiente en nuestro medio. A propósito de una revisión bianual de siete casos. Rev Clin Esp 1991; 188: 193-196.

7. Martín Sierra MC, Bernal Pérez M, Bruna Azara C, Martí Jiménez JI. Suero antiofidico: ¿peor el remedio que la enfermedad? Med Intensiva 1998; 22 148-153.

8. García de Castro S, Vela Fernández X. El manejo de las mordeduras de serpiente en Sudamérica. Emergencias 2005; 17: 267-273.

9. Juckett G, Hancox JG. Venomous snakebites in the United States: Management review and update. Am Fam Physician 2002; 65: 13671374

10. González D, Guerra JC, Pujol Borrell R, Richart C, Bacardi R. Revision de seis casos observados en nuestro medio. Med Clin 1979; 72 : 284-288.

\section{Anemia y masa abdominal en adolescente de 15 años}

\section{Sr. Director:}

La enfermedad de Castleman o hiperplasia angiofolicular es una enfermedad linfoproliferativa poco frecuente, fue descrita inicialmente en 1956 por Benjamín Castleman y su etiología es desconocida. Se presenta en adultos jóvenes y es excepcional en menores de
18 años. Desde el punto de vista clínico se describen 2 formas, una localizada o unicéntrica (ECU) de buen pronóstico, y otra multicéntrica (ECM) descrita en 1978, más frecuente en pacientes inmunodeprimidos. Histológicamente se describen 3 patrones: hialino vascular (HV), de células plasmáticas y mixto $(1,2)$. Presentamos el caso de una mujer de 15 años de edad, estudiante, sin antecedentes personales o familiares de interés. Acudió a nuestra consulta por clínica de 4 meses de evolución de astenia progresiva y sensación de disconfort abdominal. La exploración física era normal salvo palidez cutáneo mucosa. La analítica mostraba anemia microcítica, $(\mathrm{Hb}$ 6,4 g/dl, hematocrito 21, VCM 54) sin alteración del frotis sanguíneo, con ferritina, vitamina B12 y ácido fólico en rango normal. Asimismo se objetivaba una velocidad de sedimentación globular (VSG) $133 \mathrm{~mm}$ a la $1^{\text {a }}$ hora, proteína C reactiva (PCR) $124 \mathrm{mg} / \mathrm{L}$, hipergammaglobulinemia policlonal, con estudios inmunológicos y microbiológicos negativos. En las pruebas de imagen, incluido tomografía axial computerizada (TAC) de abdomen y arteriografía, se objetivó tumoración sólida de aproximadamente 3-4 cm localizada en mesenterio. Se remitió al Servicio de Cirugía Pediátrica de hospital de referencia, donde se realizó laparotomía y exéresis de la lesión, con diagnóstico de enfermedad de Castleman unicéntrica con patrón hialino vascular.

La ECM tiene una incidencia menor, se presenta en edades más tardías y con un patrón plasmocelular o mixto. Se manifiesta como una enfermedad sistémica con fiebre, sudoración, adenopatías y hepatoesplenomegalia. Es frecuente la asociación con linfomas, síndrome de POEMS o mieloma osteoesclerótico, lo que ensombrece el pronóstico. Se han intentado numerosos tratamientos con resultados desiguales dado el escaso número de casos publicados y el pequeño tamaño de las series, y en general tienen mal pronóstico. El descubrimiento en los últimos años de la asociación con el virus de la inmunodeficiencia humana (VIH) y el virus herpes humano tipo 8 (VHH-8) ha revolucionado el conocimiento de esta enfermedad, hay autores que consideran la ECM dentro del complejo de las linfadenopatias asociadas a SIDA $(3,4)$.

La ECU es la forma de presentación más frecuente, afecta a jóvenes con una edad media de 35 años. Cursa de forma asintomática, aunque en ocasiones presentan signos de compresión de estructuras adyacentes. En la exploración no suele haber adenopatías externas palpables y los datos de laboratorio suelen ser normales. En la mayoría de los casos se localiza en el mediastino, es infrecuente la forma abdominal. Los hallazgos radiológicos, tomografía axial computerizada (TAC), resonancia magnética nuclear (RMN) y angiografía, son inespecíficos y similares a otros procesos linfoproliferativos. Para el diagnóstico es necesario la resección de la masa. La biopsia por aspiración no es útil. La cirugía es curativa y no se han descrito recidivas en la literatura (5-7). Las complicaciones derivan del riesgo de evolución a linfoma, en pacientes no diagnosticados o con enfermedad irresecable.

La enfermedad de Castleman es excepcional en niños y adolescentes y presenta varias diferencias con la población adulta (8). Es muy rara la existencia de ECM y ésta tiene un curso clínico más favorable, la localización en mesenterio es habitual, no se han descrito casos de infección por VIH u otra inmunodeficiencia, y en general parece tener mejor pronóstico y evolución que en adultos (9). El patrón histológico HV es también el más frecuente y de forma típica cursa de forma asintomática y sin anemia, aunque en ocasiones, (como el caso que presentamos), en el laboratorio se objetiva una anemia microcítica-hipocrómica o normocítica, con elevación de reactantes de fase aguda e hipergammaglobulinemia (10). El tratamiento quirúrgico es curativo. Recientemente se ha introducido la angiografía y la embolización selectiva prequirúrgica como técnicas para disminuir el riesgo de hemorragia al tratarse de masas muy vascularizadas (8) En resumen, aunque infrecuente, deberíamos tener presente la enfermedad de Castleman como causa de anemia con reactantes de fase aguda y/o masa abdominal. 